\title{
Use and predictors of health services among Australian children with mental health problems: A national prospective study
}

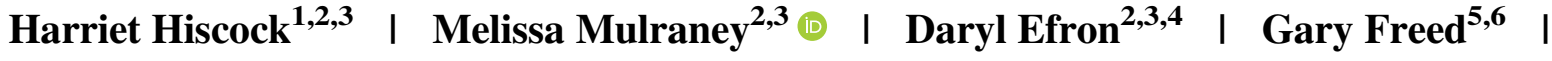 \\ David Coghill $^{3,7,8,9}$ ｜ Emma Sciberras ${ }^{2,3,10}$ | Hayley Warren ${ }^{2}$ | Michael Sawyer ${ }^{11,12}$}

\footnotetext{
${ }^{1}$ Health Services Research Unit, Royal Children's Hospital, Melbourne, Victoria, Australia

${ }^{2}$ Health Services, Murdoch Children's Research Institute, Melbourne, Victoria, Australia

${ }^{3}$ Department of Paediatrics, University of Melbourne, Melbourne, Victoria, Australia

${ }^{4}$ General Medicine, Royal Children's Hospital, Melbourne, Victoria, Australia

${ }^{5}$ Department of Paediatrics, University of Michigan, Ann Arbor, Michigan

${ }^{6}$ School of Population and Global Health, University of Melbourne, Melbourne, Victoria, Australia

${ }^{7}$ Mental Health, Royal Children's Hospital, Melbourne, Victoria, Australia

${ }^{8}$ Child Neuropsychology, Murdoch Children's Research Institute, Melbourne, Victoria, Australia

${ }^{9}$ Department of Psychiatry, University of Melbourne, Melbourne, Victoria, Australia

${ }^{10}$ Deakin Child Study Centre, Faculty of Health, School of Psychology, Deakin University, Geelong, Victoria, Australia

${ }^{11}$ Research and Evaluation Unit, Women's and Children's Health Network, North Adelaide, South Australia, Australia

${ }^{12}$ Adelaide Medical School, University of Adelaide, Adelaide, South Australia, Australia
}

\section{Correspondence}

Harriet Hiscock, Centre for Community Child Health, Royal Children's Hospital Melbourne, Flemington Road, Parkville, Melbourne, Vic. 3052, Australia.

Email: harriet.hiscock@ rch.org.au

\section{Funding information}

Clinician Scientist Fellowship; veski Inspiring Women's Fellowship; NHMRC Career Development Fellowship, Grant/ Award Number: 1110688; National Health \& Medical Research Council, Grant/Award Number: 1136222; Australian Bureau of Statistics; Australian Institute of Family Studies; Australian Government Department of Social Services; Victorian Government's Operational Infrastructure Support Program; Australian National Health and Medical Research Council, Grant/Award Number: 1129957

\begin{abstract}
Objective: Retrospective, parent-reported data suggest that 50\% of Australian children with mental health disorders miss out on care. In a national sample, we aimed to determine the proportion receiving mental health services and associated characteristics, using prospective, objective data.

Method: Prospective analysis of linked Medicare Benefits Scheme (MBS)-rebated mental health service use in children aged $8-9,10-11$, and 12-13 years, from the Longitudinal Study of Australian Children $\mathrm{K}$ cohort $(N=4,983)$. Analyses were conducted separately for children scoring above the cut points on the Strength and Difficulties Questionnaire (SDQ) emotional and externalising problems subscales. Characteristics were compared using logistic regressions.
\end{abstract}

Results: Nine to $27 \%$ of children scoring above SDQ cut points accessed MBSrebated mental health services, typically from general practitioners, psychologists and paediatricians. Greater symptom severity, parent perception that child needs help, being a young boy and older were associated with increased service use. Children from more disadvantaged families or families speaking a language other than English were less likely to receive services for internalising problems.

Conclusion: In the first prospective, objective analysis, most children do not receive mental health services. 


\section{1 | INTRODUCTION}

In Australia, $14 \%$ of 4-17-year-old or 580,000 children and adolescents meet diagnostic criteria for at least one mental health disorder over a 12-month period (Lawrence et al., 2015). Fifty percent of all mental disorders begin before the age of 14 years (Kessler et al., 2005), and their economic costs for education, social services, justice, and individual families are high (Knapp, McDaid, \& Parsonage, 2011; Whiteford et al., 2013). Reducing the incidence and burden of child and adolescent mental health disorders is therefore a priority. Effective treatments are available for common childhood mental health problems (Faraone \& Buitelaar, 2010; Ishikawa, Okajima, Matsuoka, \& Sakano, 2007) however, around $50 \%$ of Australian children and adolescents with mental health disorders do not attend any professional services for treatment (Lawrence et al., 2015). Understanding which children miss out on care could help to target interventions to improve service utilisation.

In Australia, a variety of services are available for children with mental health disorders. These include federal government-rebated services provided by health professionals (general practitioners [GPs], paediatricians, psychiatrists, psychologists, other allied health professionals) under the Medicare Benefits Scheme (MBS; Australian Government Department of Human Services, 2017), state government-funded services (hospital-based services and child and adolescent mental health services [CAMHS]), and non-government-rebated services including school-based counselling. While previous research indicates that many children are failing to use such services, these findings are largely based on retrospective, parent reports (Lawrence et al., 2015). In the 2014 National Child and Adolescent Survey of Mental Health and Wellbeing (Young Minds Matter Survey; Lawrence et al., 2015), parents reported on their child's (4-17 years) service use for emotional or behavioural problems in the previous 12 months. The most common health-care providers accessed were GPs (35\%), followed by psychologists (24\%) and paediatricians (21\%); only $7 \%$ reported accessing a child psychiatrist. Outside of the health system, $40 \%$ of parents reported that their child had accessed a school-based service. However, parents may over estimate service use. In the same Young Minds Matter Survey, 47.9\% ( $n=323 / 657$ ) of the parents who consented to MBS access and had a child aged 13-17 years who met criteria for a mental health disorder reported that their child had attended a MBS-funded health professional during the previous

\section{WHAT IS ALREADY KNOWN ABOUT THIS TOPIC}

- Up to $50 \%$ of children with mental health disorders in Australia have not accessed services in the prior 12 months.

- Studies to date have relied on retrospective, parent report of service usage among children with mental health disorders.

- It is not known if there are particular sociodemographic groups of children who are particularly at risk of missing out on services.

\section{WHAT THIS TOPIC ADDS}

- This study used linked administrative health records to examine service use objectively and prospectively.

- The majority of children with mental health difficulties do not access services.

- Girls, younger children and families speaking a language other than English are less likely to receive services.

12 months (Sawyer et al., 2018) but only $38.0 \%$ of these children had an attendance recorded in MBS data. Factors associated with parent-reported service use included more severe child mental health problems, single parent households and lower family socioeconomic status (Lawrence et al., 2015). Similarly, in a community-based sample of Australian children aged $6-8$ years $(n=179)$ who met criteria for ADHD, parents reported that $37 \%$ had not received professional services in the last 12 months (Efron, Moisuc, McKenzie, \& Sciberras, 2015). The strongest predictors of service use in this group were older child age and the degree to which the child's behaviour impacted the family.

In adolescents (see Ryan, Jorm, Toumbourou, \& Lubman, 2015 for a review), predictors of service utilisation include: female sex (Ryan, Toumbourou, \& Jorm, 2014), presence of comorbidities (Sayal, Ford, \& Goodman, 2010), poor family functioning or general family conflict (Lavigne et al., 1998), parent psychopathology (Feehan, Stanton, McGee, \& Silva, 1990), and ethnicity (Bussing, 
Koro-Ljungberg, Gary, Mason, \& Garvan, 2005). Differences in patterns of service use between Australian families living in urban versus rural locations has also been found with greater use of medical and school services in rural areas compared to greater use of specialist and allied health services in urban areas, although these data are over 10 years old (Lyneham \& Rapee, 2007).

Only three studies have conducted prospective analyses of service use (Farmer, Stangl, Burns, Costello, \& Angold, 1999; Laitinen-Krispijn, Van der Ende, Wierdsma, \& Verhulst, 1999; Ryan et al., 2014). Only one (Laitinen-Krispijn et al., 1999) used linked service data (in the Netherlands over 14 years ago) and one used parent report (conducted in the United States almost 20 years ago) (Farmer et al., 1999). Number of symptoms, parent psychopathology, perception of family impact, and health insurance cover were associated with increased likelihood of parent-reported service use (Farmer et al., 1999). An Australian study (Ryan et al., 2014) of 636 adolescents found that female sex, parent report of peer problems and hyperactivity, single-parent household, the parent being Australian born, and prior service use by the adolescent, predicted report of greater service use 12 months later.

To our knowledge, no studies have prospectively examined predictors of mental health service use in Australian children using objective, linked MBS data. We therefore examined MBS-rebated services as a first step in understanding which Australian children receive which services, given that MBS services data are objective, prospective and accounted for a large proportion of parent-reported mental health care accessed by children in the Young Minds Matter Survey.

We therefore aimed, in a sample of Australian children with mental health problems to document the number and type of MBS-rebated mental health attendances over the subsequent 18 months (Aim 1) and child (e.g., sex), family (e.g., parent mental health), and geographical (e.g., neighbourhood socioeconomic status) characteristics associated with this service use (Aim 2). We hypothesised that most children experiencing mental health problems would not go on to attend an MBS-rebated mental health service and older children, those with more severe mental health problems, and children living in more advantaged, metropolitan areas would be more likely to access mental health services.

\section{2 | METHODS}

\section{1 | Participants and procedure}

Data were drawn from the Longitudinal Study of Australian Children (LSAC), a nationally representative longitudinal study. The sampling design and field methods for the first wave of data have been described elsewhere (Soloff, Lawrence, \& Johnstone, 2005). Briefly, LSAC used a two-stage clustered design with Medicare Australia enrolment as the sampling frame and Australian postcodes as primary sampling units. Postcode stratification by state of residence and urban versus rural status ensured proportional numbers of children (according to population statistics) were randomly selected within each postcode. LSAC data collection was started in 2004. Children from non-English-speaking families and those living in rental properties were under-represented, while children with more highly educated parents were over-represented. Data were drawn from the kindergarten cohort $(\mathrm{K})$ of children aged 4-5 years at enrolment $(N=4,983)$. Succeeding data waves have been collected every 2 years, $79.4 \%$ of the sample $(n=3,956)$ remained in the study at Wave 5 (child age 12-13 years). Retention was slightly lower for children from non-English-speaking backgrounds and whose mothers were less highly educated (Cusack \& Defina, 2013).

For the purpose of the present study, we analysed data from Waves 3 (age 8-9 years), 4 (age 10-11 years), and 5 (age 12-13 years). In November 2006, the Australian government introduced a new MBS item schedule for mental health services for GP Mental Health treatment. Prior to this time, it was not possible to distinguish between GP visits for physical versus mental health, and as such, Waves 1 and 2 do not provide equivalent data. We also excluded Wave 6 as 18-month prospective data required for our analyses are not yet available.

LSAC data are obtained via a face-to-face interview conducted by trained researchers in the child's home, and written questionnaires distributed at the interview are completed by primary and secondary caregivers. We included available data from each child's primary caregiver (in most cases, the child's biological mother). The study was approved by the Australian Institute of Family Studies Ethics Committee, and written informed consent was provided by a caregiver of each child.

\section{2 | Measures}

\subsection{1 | Mental health service use (outcome)}

We measured service use through linked child MBS utilisation data (93\% of sample linked). At each wave, we compiled the MBS schedule item data to examine mental health service use over the 18 months after survey completion, among those who scored above the Strengths and Difficulties Questionnaire (SDQ) clinical cut points (see below). We chose 18 months because parents completed the SDQ every 24 months and this measure asks about the child's mental health over the preceding 6 months. 
We included the following health professional services/categories of MBS items to construct our mental health service use outcome: (a) GP mental health treatment; (b) psychologist; (c) psychiatrist; (d) family therapy; and (e) allied health (occupational therapist or social worker) delivery of focused psychological strategies. We also included whether the child had redeemed a prescription for a psychotropic medication through linked Pharmaceutical Benefits Scheme (PBS) data. Within LSAC the psychotropic medications redeemed through the PBS included: antidepressants, antipsychotics, ADHD medications (methylphenidate, dexamphetamine, or atomoxetine), benzodiazepines, clonidine, and anti-epileptics/mood stabilisers.

Mental health care provided by paediatricians is not identifiable through unique MBS items. However, a recent audit of Australian paediatricians $(n=180)$ found that $60 \%$ of new and $66 \%$ review visits involved the treatment of developmental/behavioural issues (Hiscock et al., 2017). As such, for Aim 1, we present frequencies of attendance to a health professional for mental health treatment, and separately, attendances to a paediatrician.

\subsection{2 | Child mental health problems}

We used the SDQ, a validated 25-item screening measure that asks about the child's behaviour over the previous 6 months. It consists of five subscales (emotional problems, conduct problems, peer problems, hyperactivity/inattention, and prosocial behaviour). Each subscale has a cut off that can be used to indicate whether the child's behaviour is of concern for a mental health difficulty. We utilised the parent-reported emotional problems, conduct problems, and hyperactivity/inattention subscales to categorise children into the clinical or normal range for emotional problems (a score of 5 or higher) or externalising problems (scoring either 4 or higher on the conduct problems subscale, or 7 or higher on the hyperactivity/inattention subscale), respectively. The validation study of the SDQ found that $46.3 \%$ of children who scored in the clinical range met full diagnostic criteria for a psychiatric disorder, compared to just 5.4\% of children who scored below the clinical cut point (Goodman, 2001).

\subsection{3 | Characteristics associated with service use}

We identified, a priori, child, family and geographical characteristics potentially associated with service use including:

1. Child: sex and severity of symptoms.

2. Family: type (single vs. two parent home), main language spoken at home (English vs. other), and primary caregiver high school completion. Individual family socioeconomic position (SEP) was estimated by a composite variable derived by ranking each family's relative SEP based on combined household parental income, education, and occupational prestige (Blakemore, Strazdins, \& Gibbings, 2009). The unweighted average variable at each LSAC wave was then standardised within each wave to have a mean of 0 , and $S D$ of 1. Higher scores represent a better SEP. Parental psychosocial distress was estimated using the self-reported Kessler-6 (K6) scale, a standardised and validated measure of psychological distress (Furukawa, Kessler, Slade, \& Andrews, 2003). Higher scores reflect more distress. Family functioning was measured using a LSAC study-designed item: "Sometimes family members may have difficulty getting along with one another. They don't always agree and they may get angry. In general, how would you rate your family's ability to get along with one another?", on a 5-point scale from 1 ("Excellent") to 5 ("Poor"). Parental conflict was estimated using the self-reported argumentative relationships scale (Zubrick et al., 2008) where four items (e.g., "How often do you and your partner argue?", "How often do you and your partner disagree about basic child-rearing issues?") are scored on a 5-point scale from 1 ("Never") to 5 ("Always"). Higher overall mean scores indicate a more argumentative relationship. Parental perception that child needs help was measured using responses (yes/no) to two items derived from the Ontario Child Health Study (Boyle et al., 1987), that is, "Does study child ever need more help or care than other children his/her own age for coping with feelings or emotions?", "Does study child ever need more help or care than other children his/her own age for managing his/her own behaviour?"

3. Geographical characteristics: Location of primary residence (higher scores indicate greater remoteness), and family neighbourhood disadvantage, measured by the Socio-Economic Indexes for Areas (Pink, 2013) Relative Disadvantage Index (higher scores reflect less disadvantage $[M=1,000, S D=100])$.

\section{3 | Statistical analysis}

For each wave of data collection, we selected children who scored above the clinical cut point on the SDQ emotional problems or SDQ externalising problems subscales. We conducted separate analyses for these two groups of children to determine whether service use differed by type of mental health problem.

First, at each wave, we used descriptive statistics to summarise services used (Aim 1) and sociodemographic 
characteristics of those who did versus did not go on to access services over the subsequent 18 months. We compared characteristics using bivariate logistic regressions (Aim 2). We attempted to conduct multivariate logistic regression analyses but valid models could not be constructed due to the small number of children who received services. For the prospective 18-month service use, we present frequencies of attendance to a health professional for mental health treatment, and separately, attendances to a paediatrician. We ran analyses with and without survey weights, given that we obtained similar results from both analyses we have chosen to present weighted results only.

\section{3 | RESULTS}

Eighty-one percent of children were in the normal range of emotional problems at all time points (ages 8-9, 10-11, $12-13$ years). Three to $5 \%$ of children scored above the emotional problems cut off at only one time point, $1-3 \%$ of children at two time points, and a little over $2 \%$ of children scored in the clinical range at all three time points. For externalising problems, these proportions were $78 \%, 3-4 \%$, $1-3 \%$, and a little more than $5 \%$, respectively. At each time point, between 4 and $7 \%$ of children scored in the clinical range for emotional problems only, $8-12 \%$ for externalising symptoms only, and 3-4\% scored above cut off on both emotional problems and externalising symptom subscales.

\section{1 | Number and types of MBS-rebated mental health attendances over the subsequent 18 months (Aim 1)}

Most children scoring above the SDQ cut points did not access any MBS-rebated mental health services in the subsequent 18 months following survey completion (Table 1). Children who did access mental health services were likely to attend two or more appointments. Across all ages, children with emotional problems were more likely to receive mental health services (15-27\%) than children with externalising problems (9-20\%). Children were more likely to redeem a prescription for a psychotropic medication if they were older, and there was a slightly higher rate of prescriptions redeemed for children with externalising problems than those with emotional problems.

Figure 1 shows the frequency of health attendances by provider type, by sex. Across all ages, males tended to receive more health services than females, particularly paediatrician services, despite having similar levels of mental health symptoms. Although 12-13-year-old girls appeared

TA B LE 1 Weighted frequency of visits to health professionals for a mental health service and to paediatricians over the next 18 months for children above cut off on the Strength and Difficulties Questionnaire

\begin{tabular}{|c|c|c|c|c|c|c|c|}
\hline & $\begin{array}{l}\text { Psychotropic } \\
\text { medication use } \\
\text { At least one } \\
\text { prescription (\%) }\end{array}$ & $\begin{array}{l}\text { No } \\
\text { appointment } \\
(\%)\end{array}$ & $\begin{array}{l}\text { Single } \\
\text { appointment } \\
(\%)\end{array}$ & $\begin{array}{l}\geq 2 \\
\text { appointments } \\
(\%)\end{array}$ & $\begin{array}{l}\text { No } \\
\text { appointment } \\
(\%)\end{array}$ & $\begin{array}{l}\text { Single } \\
\text { appointment } \\
(\%)\end{array}$ & $\begin{array}{l}\geq 2 \\
\text { appointments } \\
(\%)\end{array}$ \\
\hline \multicolumn{8}{|l|}{$8-9$ years } \\
\hline $\begin{array}{l}\text { Above cut off on } \\
\text { emotional symptoms }\end{array}$ & 10.2 & 85.3 & 4.6 & 10.1 & 77.6 & 6.2 & 16.2 \\
\hline $\begin{array}{l}\text { Above cut off on } \\
\text { externalising } \\
\text { symptoms }\end{array}$ & 12.6 & 90.9 & 3.3 & 5.8 & 75.1 & 7.2 & 17.7 \\
\hline \multicolumn{8}{|l|}{$10-11$ years } \\
\hline $\begin{array}{l}\text { Above cut off on } \\
\text { emotional symptoms }\end{array}$ & 13.5 & 82.0 & 3.9 & 14.1 & 76.8 & 7.6 & 15.6 \\
\hline \multicolumn{8}{|l|}{$12-13$ years } \\
\hline $\begin{array}{l}\text { Above cut off on } \\
\text { emotional symptoms }\end{array}$ & 17.1 & 73.0 & 7.1 & 19.9 & 81.6 & 9.1 & 9.3 \\
\hline $\begin{array}{l}\text { Above cut off on } \\
\text { externalising } \\
\text { symptoms }\end{array}$ & 19.5 & 79.9 & 5.6 & 14.5 & 78.9 & 8.7 & 12.4 \\
\hline
\end{tabular}


more likely to see GPs and psychologists than boys. A larger proportion of children received an MBS service from a paediatrician $(13-28 \%)$ than a psychologist $(1-20 \%)$ or psychiatrist $(0-5 \%)$. There was a substantially higher rate of paediatrician attendance among children with emotional (19-23\%) and externalising problems (21-22\%) compared to those without such problems (6-7\%), suggesting that between 12 and $17 \%$ of children were attending paediatricians only for their mental health.

\section{2 | Characteristics associated with service use in the subsequent 18 months (Aim 2)}

Few variables were consistently associated with subsequent mental health service use (Table 2). The strongest predictor was symptom severity. Younger boys were more likely than younger girls to access services. Children were more likely to access services if their parents thought that they needed help. Children from families who spoke a language other than English were less likely to receive services for emotional but not externalising problems.

\section{4 | DISCUSSION}

This is the first Australian study to document mental health service use by children with mental health problems
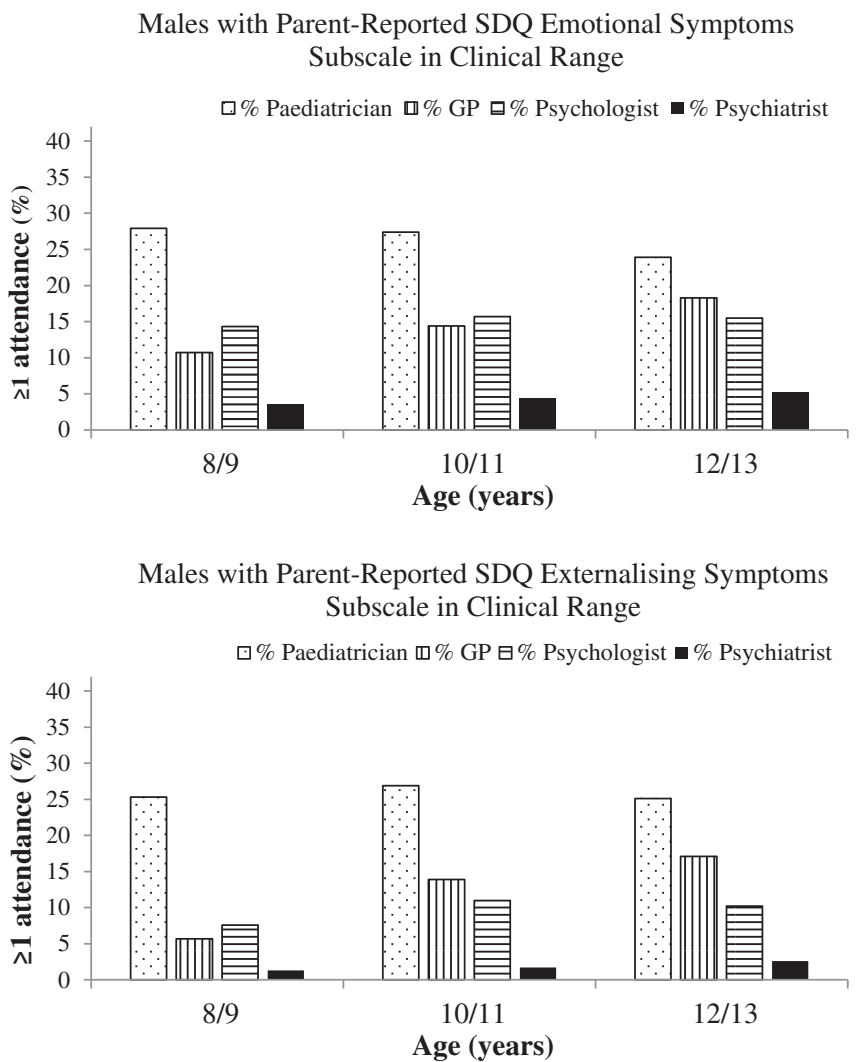

prospectively, using linked MBS data. Most children received no MBS-rebated services. GPs, psychologists, and paediatricians provided the majority of MBS-rebated services. For children scoring above SDQ emotional and externalising cut points, the most consistent factors associated with getting services were symptom severity and parent perception that the child needed help for their problem. Overall, girls were less likely to receive services than boys, as were younger children. Children were more likely to redeem a prescription for a psychotropic medication if they were older or had externalising problems.

Our findings are similar to those of the Young Minds Matter Survey in terms of low overall service use, increased use by older children and those with more severe symptoms (Sawyer et al., 2018). Increased use by older children may be a cohort and/or an age effect. Medicare-rebated psychology services were introduced in 2006. However, there are no published data on change in use of Medicare-rebated psychology services by children. While there has been an overall increase in the use of these services by Australians generally (from 5.7\% in 2008-2009 to 9.8\% in 2016-2017), none of the Australian Institute of Welfare mental health reports from 2011 to 2016, inclusive, detail children's use of such services. In 2016-2017, children under the age of 15 years had the lowest use of Medicare-rebated mental
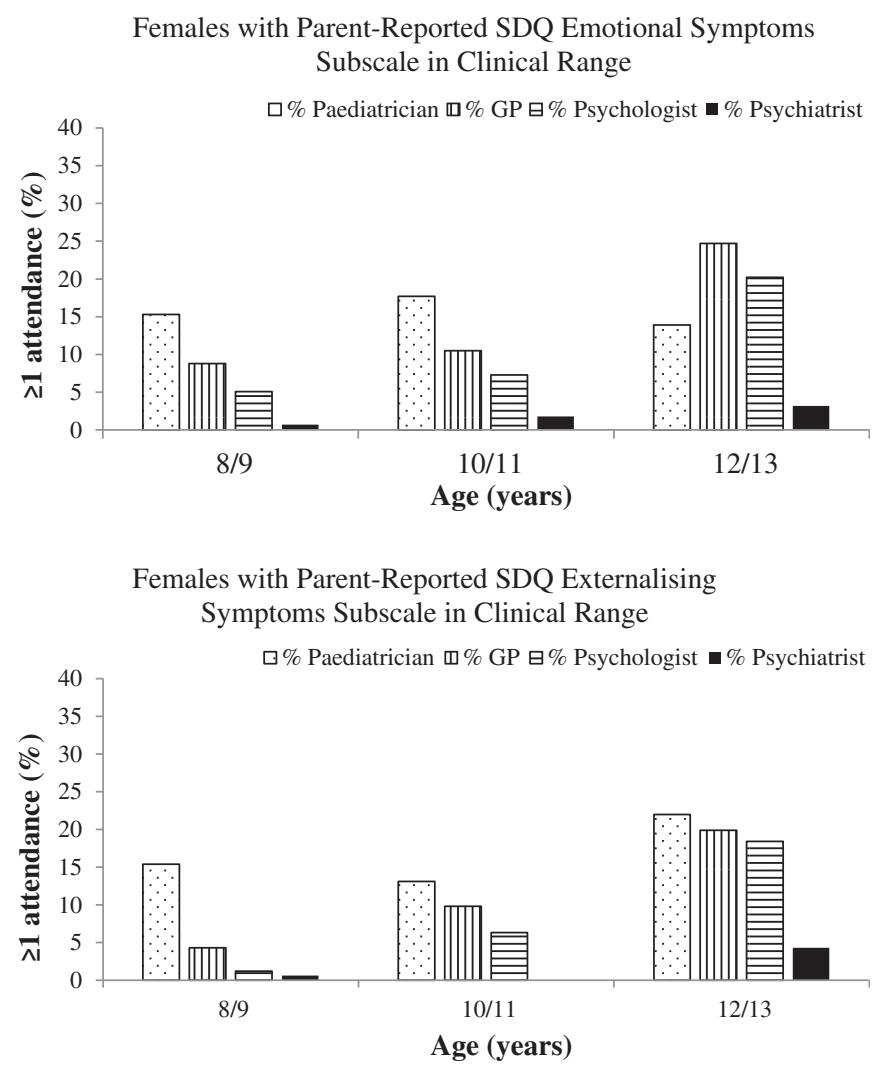

F I G U RE 1 Frequency of health attendances by provider type and child sex and age 
T A B L E 2 Weighted characteristics of children at ages 8-9, 10-11 and 12-13 years who did versus did not attend mental health services over the next 18 months using survey weights

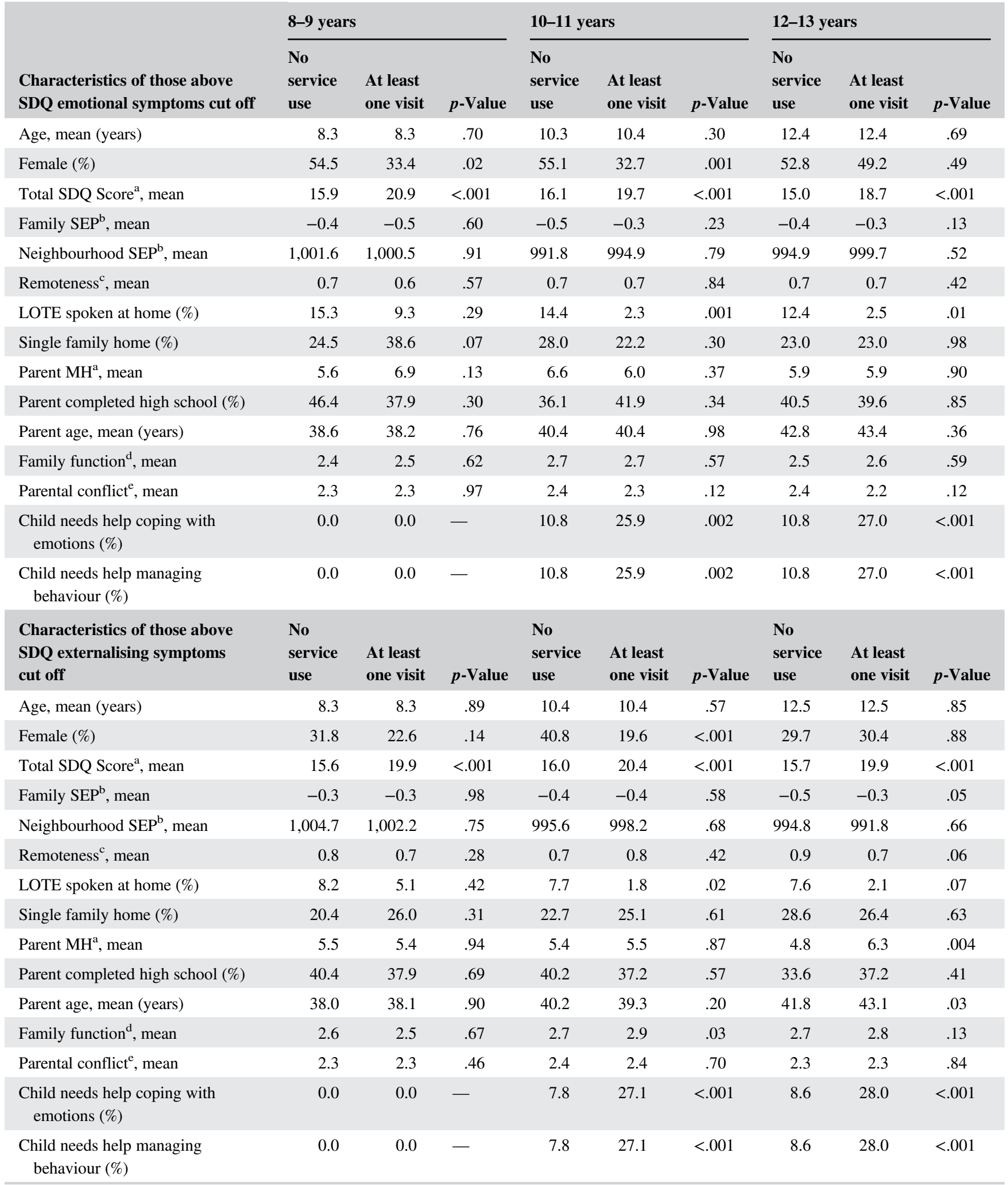

Abbreviations: LOTE, Language Other Than English; MH, Mental Health; SDQ, Strength and Difficulties Questionnaire; SEP, socioeconomic position.

${ }^{\mathrm{a}}$ Higher scores represent poorer mental health.

${ }^{\mathrm{b}}$ Higher scores represent less disadvantage.

${ }^{c}$ Higher scores represent more disadvantage.

${ }^{\mathrm{d}}$ Higher scores represent poorer family functioning.

${ }^{\mathrm{e}}$ Higher scores represent more conflict. 
health services $(5.1 \%)$ (Australian Institute of Health and Welfare, 2018).

Contrary to the Young Minds Matter Survey, we found little to no increase in service use in children from families of low socioeconomic status or single parents. This may be because Young Minds Matter included school-based services, community health services and publicly funded CAMHS which typically carry no out-of-pocket cost to families and may therefore be more accessible for low income or single parents. Alternatively, there was some selective attrition over time in LSAC so that low SES families were less likely to remain in the study (Cusack \& Defina, 2013) and as such the SES distribution may have been different in the two studies. It may also be because we used linked MBS data to quantify service use which is not subject to recall or response bias. Parents do overestimate services use (Sawyer et al., 2018) but whether parents from low socioeconomic status do this more, is unknown. In adults, one study comparing survey to administrative data found that underreporting of mental health service use decreased in people with higher educational levels (Drapeau, Boyer, \& Diallo, 2011).

We did find that children from families who spoke a language other than English were less likely to receive services for their emotional problems. By their nature, emotional problems are harder to detect than externalising problems. This may be particularly pronounced in children with English as a second language as their quietness in the classroom may be mistaken for a language issue rather than a mental health issue. Different cultural norms may also preclude their parents from seeking help even if they suspect their child to have a problem. Further, parents who speak a language other than English may struggle to find mental health services for their child who speaks their own language (Australian Institute of Health and Welfare, 2018).

Our finding that children were more likely to use services as they got older is not surprising, as parents of younger children may believe their child will "grow out" of their mental health problems and so not seek treatment (The Royal Children's Hospital, 2017), even when their child's symptoms are above a clinical cut point. Australian parents are also less likely to recognise that a younger child has a mental health problem than an older child (Huang, Hiscock, \& Dalziel, 2018). Further, the gradual onset and increase in severity over time of many mental health problems means that children and their parents are more likely to seek services when the symptoms become severe or impact significantly on functioning, typically as children grow older. Across ages and emotional and externalising mental health problems, boys were generally more likely to attend services than girls. Boys are more likely to experience externalising problems which are more readily detected than emotional problems (Abbas et al., 2017; Lyneham \& Rapee, 2007).

Our study had a number of strengths. We analysed data from a nationally representative sample and used linked MBS items to determine prospective service use. However, we were unable to report on non-MBS mental health services provided via CAMHS, headspace, the Access to Allied Psychologists Scheme (ATAPS), or school-based services. Due to the current MBS item structure for paediatrician services, we were unable to completely differentiate care provided by paediatricians for mental versus physical health problems. Similarly, although GPs do have specific mental health MBS item numbers, anecdotal reports suggest they do not always use them. Hence our results may underestimate the mental health services provided by GPs to children. However, we did also include redemption of a psychotropic medication in our definition of mental health service use. We believe this has captured some mental health appointments billed as a generic consultation. We used parent report of emotional problems which is not as accurate as self-report (Hope et al., 1999). However, this is likely to underestimate the presence of emotional problems in the sample and as such provides a conservative approach. We used a mental health screening survey rather than diagnostic interviews and as such some children scoring in the clinical range may not need services.

The vast majority of Australian children with mental health problems are not getting care. Future research is needed to better understand system, parent and child drivers of why children miss out on care, particularly girls and younger children. Barriers and enablers of accessing services need to be better understood across all families. This will require in-depth interviews with families, children and service providers. Providing paediatricians with separate MBS item numbers for mental health care, changing the Medicare system to include a main reason for consultation for generic consultations, and making service use data readily available for linkage across non-MBS funded services (e.g., CAMHS, ATAPS, headspace, and school services) could enhance future analyses of objective measurement of mental health service use for Australian children.

\section{ACKNOWLEDGEMENTS}

This project was funded by a Project Grant from the Australian National Health and Medical Research Council (NHMRC) (1129957). MCRI is supported by the Victorian Government's Operational Infrastructure Support Program. LSAC is supported by the Australian Government Department of Social Services, the Australian Institute of Family Studies and the Australian Bureau of Statistics. H.H. is supported by an NHMRC Practitioner Fellowship 113622. 
E.S. is funded by an NHMRC Career Development Fellowship 1110688 (2016-2019) and a veski Inspiring Women's Fellowship (2017-2019). D.E. is funded by a Clinician Scientist Fellowship from MCRI.

\section{ORCID}

Melissa Mulraney (1) https://orcid.org/0000-0003-1953-6481

\section{REFERENCES}

Abbas, S., Ihle, P., Adler, J.-B., Engel, S., Günster, C., Holtmann, M., ... Lehmkuhl, G. (2017). Predictors of non-drug psychiatric/psychotherapeutic treatment in children and adolescents with mental or behavioural disorders. European Child \& Adolescent Psychiatry, 26(4), 433-444. https://doi.org/10.1007/s00787-0160900-z

Australian Government Department of Human Services. (2017). Medicare statistics. Retrieved from https://www.humanservices.gov.au/ organisations/about-us/statistical-information-and-data/medicare-sta tistics

Australian Institute of Health and Welfare. (2018, October 11). Mental Health Services in Australia. Retrieved from https://www.aihw.gov. $\mathrm{au} / \mathrm{reports} / \mathrm{mental}$-health-services/mental-health-services-in-australia/ report-contents/summary

Blakemore, T., Strazdins, L., \& Gibbings, J. (2009). Measuring family socioeconomic position. Australian Social Policy, 8, 121-168.

Boyle, M. H., Offord, D. R., Hofmann, H. G., Catlin, G. P., Byles, J. A., Cadman, D. T., ... Szatmari, P. (1987). Ontario child health study: I. Methodology. Archives of General Psychiatry, 44 (9), 826-831. https://doi.org/10.1001/archpsyc.1987.0180021007 8012

Bussing, R., Koro-Ljungberg, M. E., Gary, F., Mason, D. M., \& Garvan, C. W. (2005). Exploring help-seeking for ADHD symptoms: A mixed-methods approach. Harvard Review of Psychiatry, 13(2), 85-101. https://doi.org/10.1080/10673220590956465

Cusack, B., \& Defina, R. (2013). Longitudinal Study of Australian Children Technical Paper No. 10: Wave 5 weighting and non response. Melbourne, Australia: Australian Insititute of Family Studies.

Drapeau, A., Boyer, R., \& Diallo, F. B. (2011). Discrepancies between survey and administrative data on the use of mental health services in the general population: Findings from a study conducted in Quebec. BMC Public Health, 11(1), 837. https://doi.org/10.1186/14712458-11-837

Efron, D., Moisuc, O., McKenzie, V., \& Sciberras, E. (2015). Service use in children aged 6-8 years with attention deficit hyperactivity disorder. Archives of Disease in Childhood, 101(2), 161-165. https://doi.org/10.1136/archdischild-2015-309520

Faraone, S. V., \& Buitelaar, J. (2010). Comparing the efficacy of stimulants for ADHD in children and adolescents using meta-analysis. European Child \& Adolescent Psychiatry, 19(4), 353-364. https:// doi.org/10.1007/s00787-009-0054-3

Farmer, E. M., Stangl, D. K., Burns, B. J., Costello, E. J., \& Angold, A. (1999). Use, persistence, and intensity: Patterns of care for children's mental health across one year. Community Mental Health Journal, 35(1), 31-46. https://doi.org/10.1023/A:1018 743908617
Feehan, M., Stanton, W., McGee, R., \& Silva, P. A. (1990). Parental helpseeking for behavioural and emotional problems in childhood and adolescence. Australian and New Zealand Journal of Public Health, 14(3), 303-309. https://doi.org/10.1111/j.1753-6405.1990.tb00631.x

Furukawa, T. A., Kessler, R. C., Slade, T., \& Andrews, G. (2003). The performance of the K6 and K10 screening scales for psychological distress in the Australian National Survey of Mental Health and Well-Being. Psychological Medicine, 33(02), 357-362. https://doi. org/10.1017/S0033291702006700

Goodman, R. (2001). Psychometric properties of the Strengths and Difficulties Questionnaire. Journal of the American Academy of Child and Adolescent Psychiatry, 40(11), 1337-1345. https://doi.org/10. 1097/00004583-200111000-00015

Hiscock, H., Danchin, M. H., Efron, D., Gulenc, A., Hearps, S., Freed, G. L., ... Wake, M. (2017). Trends in paediatric practice in Australia: 2008 and 2013 national audits from the Australian Paediatric Research Network. Journal of Paediatrics and Child Health, 53, 55-61. https://doi.org/10.1016/S0140-6736(13)61611-6

Hope, T. L., Adams, C., Reynolds, L., Powers, D., Perez, R. A., \& Kelley, M. L. (1999). Parent vs. self-report: Contributions toward diagnosis of adolescent psychopathology. Journal of Psychopathology and Behavioral Assessment, 21(4), 349-363. https://doi.org/10. 1023/A:1022124900328

Huang, L., Hiscock, H., \& Dalziel, K. M. (2018). Parents' perception of children's mental health: Seeing the signs but not the problems. Archives of Disease in Childhood. https://doi.org/10.1136/ archdischild-2018-315829

Ishikawa, S. I., Okajima, I., Matsuoka, H., \& Sakano, Y. (2007). Cognitive behavioural therapy for anxiety disorders in children and adolescents: A meta-analysis. Child and Adolescent Mental Health, 12(4), 164-172. https://doi.org/10.1111/j.1475-3588.2006. 00433.x

Kessler, R. C., Berglund, P., Demler, O., Jin, R., Merikangas, K. R., \& Walters, E. E. (2005). Lifetime prevalence and age-of-onset distributions of DSM-IV disorders in the National Comorbidity Survey Replication. Archives of General Psychiatry, 62(6), 593-602. https://doi.org/10.1001/archpsyc.62.6.593

Knapp, M., McDaid, D., \& Parsonage, M. (2011). Mental health promotion and mental illness prevention: The economic case. London, England: Department of Health.

Laitinen-Krispijn, S., Van der Ende, J., Wierdsma, A. I., \& Verhulst, F. C. (1999). Predicting adolescent mental health service use in a prospective record-linkage study. Journal of the American Academy of Child \& Adolescent Psychiatry, 38(9), 1073-1080. https://doi.org/10.1097/00004583-199909000-00009

Lavigne, J. V., Arend, R., Rosenbaum, D., Binns, H. J., Christoffel, K. K., Burns, A., \& Smith, A. (1998). Mental health service use among young children receiving pediatric primary care. Journal of the American Academy of Child \& Adolescent Psychiatry, 37(11), 1175-1183. https://doi.org/10.1097/00004583199811000-00017

Lawrence, D., Johnson, S., Hafekost, J., Boterhoven de Haan, K., Sawyer, M., Ainley, J., \& Zubrick, S. R. (2015). The mental health of children and adolescents: Report on the second Australian child and adolescent survey of mental health and wellbeing. Canberra, Australia: Department of Health.

Lyneham, H. J., \& Rapee, R. M. (2007). Childhood anxiety in rural and urban areas: Presentation, impact and help seeking. Australian Journal of Psychology, 59(2), 108-118. https://doi.org/10.1080/ 00049530701317082 
Pink, B. (2013). Technical paper: Socio-economic indexes for areas (SEIFA) 2011. Canberra, Australia: Australian Bureau of Statistics.

Ryan, S. M., Jorm, A. F., Toumbourou, J. W., \& Lubman, D. I. (2015). Parent and family factors associated with service use by young people with mental health problems: A systematic review. Early Intervention in Psychiatry, 9(6), 433-446. https://doi.org/10.1111/eip.12211

Ryan, S. M., Toumbourou, J. W., \& Jorm, A. F. (2014). Factors associated with service use for young adolescents with mental health problems: Findings from an Australian longitudinal study. SAGE Open, 4(4), 1-9. https://doi.org/10.1177/2158244014556286

Sawyer, M. G., Reece, C. E., Sawyer, A. C., Hiscock, H., Lawrence, D. J. A., \& Psychiatry, N. Z. J. O. (2018). Adequacy of treatment for child and adolescent mental disorders in Australia: A national study. Australian and New Zealand Journal of Psychiatry, 53(4), 326-335. https://doi.org/10.1177/0004867418808895

Sayal, K., Ford, T., \& Goodman, R. (2010). Trends in recognition of and service use for attention-deficit hyperactivity disorder in Britain, 1999-2004. Psychiatric Services, 61(8), 803-810. https://doi. org/10.1176/ps.2010.61.8.803

Soloff, C., Lawrence, D., \& Johnstone, R. (2005). LSAC Technical Paper No. 1: Sample design. Melbourne, Australia: Australian Institute of Family Studies.
The Royal Children's Hospital. (2017). Child Health Poll. Retrieved from https://www.rchpoll.org.au/polls/child-mental-health-problem scan-parents-spot-the-signs/

Whiteford, H. A., Degenhardt, L., Rehm, J., Baxter, A. J., Ferrari, A. J., Erskine, H. E., ... Johns, N. (2013). Global burden of disease attributable to mental and substance use disorders: Findings from the Global Burden of Disease Study 2010. Lancet, 382(9904), 1575-1586. https://doi.org/10.1016/S0140-6736(13)61611-6

Zubrick, S. R., Smith, G. J., Nicholson, J., Sanson, A., \& Jackiewicz, T. A. (2008). Parenting and Families in Australia. FaHCSIA Social Policy Research Paper. http://dx.doi.org/10.2139/ ssrn. 1703269

How to cite this article: Hiscock H, Mulraney M, Efron D, et al. Use and predictors of health services among Australian children with mental health problems: A national prospective study. Aust J Psychol. 2020;72:31-40. https://doi.org/10.1111/ ajpy. 12256 